\title{
Systemic Low-Grade Inflammation and Risk of Coronary Heart Disease: Results from the MONICA/KORA Augsburg Cohort Studies
}

\author{
W. Koenig ${ }^{1}$ \\ C. Meisinger ${ }^{2,3}$ \\ J. Baumert ${ }^{2}$ \\ N. Khuseyinova ${ }^{1}$ \\ H. Löwel ${ }^{2,3}$
}

\author{
Systemische Entzündung und Risiko für eine koronare Herzkrankheit: Ergebnisse \\ der MONICA/KORA-Augsburg-Kohortenstudien
}

\section{Zusammenfassung}

Die Atherosklerose weist wesentliche Charakteristika einer lokalen Inflammation auf und ist von einer geringgradigen systemischen inflammatorischen Antwort begleitet. Zahlreiche prospektive Studien bei initial gesunden Personen, aber auch bei Patienten mit bereits klinisch manifester Atherosklerose zeigen eine starke, unabhängige Beziehung zwischen nur geringgradig erhöhten Konzentrationen verschiedener systemischer Inflammationsmarker (Plasmaviskosität, C-reaktives Protein [CRP] oder anderen Akute-Phase-Reaktanten) und verschiedenen kardiovaskulären Endpunkten. Derzeit liegen die umfangreichsten und konsistentesten Daten für CRP vor. Erste Ergebnisse zeigen, dass CRP in der Lage ist, die im Framingham-Risiko-Score enthaltene Information zu modifizieren und unlängst veröffentlichte Richtlinien von AHA/CDC empfehlen die Bestimmung von CRP bei asymptomatischen Personen mit mittlerem Risiko (10-Jahresrisiko zwischen 10 und 20\%) und bei ausgewählten Patienten nach einem akuten Koronarsyndrom. Derzeit wird in einer großen randomisierten Therapiestudie der Frage nachgegangen, ob erhöhte CRP-Spiegel eventuell ein zusätzliches Kriterium zur Statin-Behandlung von Personen mit normalem LDL-Cholesterin darstellen. Forschungsergebnisse der letzten Jahre legen nahe, dass CRP möglicherweise nicht nur ein kardiovaskulärer Risikomarker ist, sondern direkt in den Prozess der Atherogenese involviert ist. Letztlich wird derzeit eine Fülle weiterer inflammatorischer Biomarker daraufhin untersucht, ob sie die Prädiktion kardiovaskulärer Ereignisse bei verschiedenen Personengruppen verbessern können. Wir haben im Rahmen der MONICA/KORA-

\section{Abstract}

Atherosclerosis is characterised by a non-specific local inflammatory process accompanied by a systemic response. A number of prospective studies in initially healthy subjects and in patients with manifest atherosclerosis have now convincingly demonstrated a strong and independent association between even slightly elevated concentrations of various systemic markers of inflammation (plasma viscosity, C-reactive protein [CRP], and other acute phase reactants) and a number of cardiovascular endpoints. Presently, CRP, the classical acute phase protein, seems to be the marker of choice for the clinical situation. Initial evidence suggests that measurement of CRP adds to global risk assessment based on the Framingham risk score. The recent AHA/CDC consensus report recommends the measurement of CRP in asymptomatic subjects at intermediate risk for future coronary events (10-year risk of $10-20 \%$ ) and in selected patients after an acute coronary syndrome. Whether CRP shall alter treatment strategies in subjects without clinically manifest atherosclerosis is presently being tested in a large randomised clinical trial. In addition, recent research has suggested that CRP may not only be a risk marker, but may be directly involved in the pathogenesis of atherothrombosis. However, there are other emerging biomarkers. Lipoprotein-associated phospholipase $\mathrm{A}_{2}\left(\mathrm{Lp}_{\mathrm{PLA}}\right)$, an enzyme produced by monocytes/macrophages, T-cells and mast cells was found to generate proinflammatory and proatherogenic molecules from oxidised LDL. We tested the association of these new biomarkers with traditional risk factors

affiliation

${ }^{1}$ University of Ulm Medical Center, Department of Internal Medicine II-Cardiology, Ulm, Germany

${ }^{2}$ GSF - National Research Center for Environment and Health, Institute of Epidemiology, Neuherberg, Germany

${ }^{3}$ Augsburg Central Hospital, MONICA/KORA Myocardial Infarction Registry, Augsburg, Germany

correspondence

Prof. Dr. Wolfgang Koenig, FESC, FACC · University of Ulm Medical Center, Dept. of Internal Medicine II Cardiology · Robert-Koch-Straße 8 · 89081 Ulm · Germany · E-mail: wolfgang.koenig@medizin.uni-ulm.de

bibliography

Gesundheitswesen 2005; 67 Sonderheft 1: S62 -S67 @ Georg Thieme Verlag KG Stuttgart · New York DOI 10.1055/s-2005-858246

ISSN 0949-7013 
Studien die Assoziation einer Reihe derartiger Biomarker mit klassischen kardiovaskulären Risikofaktoren und mit koronaren Ereignissen untersucht.

\section{Schlüsselwörter}

Inflammation · Biomarker · koronare Ereignisse · Querschnittsstudien · prospektive Studien and their ability to predict incident coronary events, using the MONICA/KORA database.

\section{Key words}

Inflammation · biomarkers · coronary events · cross-sectional studies $\cdot$ prospective studies

\section{Introduction}

Inflammation in the vessel wall is now considered to play an essential role in the initiation, progression and the final pathophysiologic steps of atherosclerosis, plaque erosion or fissure, and eventually plaque rupture [1]. Classical pathologic studies show the presence of inflammatory cells, like monocyte-derived macrophages and T-lymphocytes not only at the site of rupture or superficial erosion but rather at every stage of the disease [2, 3]. These morphologic changes are preceded by dysfunction of activated endothelial cells which produce adhesion molecules that interact with inflammatory cells. The ability of monocytederived macrophages to secrete various cytokines, chemokines, growth-factors, and disintegrins, further leads to activation and proliferation of smooth muscle cells, lesion progression, and finally to the weakening of a vulnerable plaque by matrix degradation of its fibrous cap [4]. Yet atherosclerosis and its clinical complications are not only characterized by a local inflammation. Recent prospective studies have consistently shown that several markers of systemic inflammation may be used to predict future cardiovascular events not only in apparently healthy subjects, but also in patients with manifest atherosclerosis. Measurements of inflammatory markers add to the predictive value of total and HDL cholesterol in assessing coronary risk long-term [5]. This suggests that the evaluation of the ,active', inflammatory state of patients with manifest atherosclerosis yields important prognostic information.

Within the MONICA/KORA Augsburg cohort studies we had the opportunity to evaluate several markers of inflammation (plasma viscosity, C-reactive protein and Lp-PLA 2 ) for their ability to predict coronary heart disease (CHD) events in initially healthy subjects randomly drawn from the general population.

\section{Plasma viscosity}

Plasma viscosity is determined by various macromolecules, e.g. fibrinogen, immunoglobulins, and lipoproteins. It may therefore reflect several aspects involved in cardiovascular diseases, including the effects of classical risk factors, hemostatic disturbances, and inflammation. We examined the association of plasma viscosity with the incidence of a first major CHD event (fatal and non-fatal myocardial infarction, MI, and sudden cardiac death, $\mathrm{n}=50$ ) in 933 men aged $45-64$ years participating in the first MONICA survey in 1984/85 (S1). The incidence rate was 7.23 per 1000 person-years (95\% confidence interval, CI, 5.37-9.53) and the subjects were followed for 8 years. All suspected cases of incident CHD were classified according the MONICA protocol. There was a positive and statistically significant association be- tween baseline levels of plasma viscosity and incident CHD even after controlling for a variety of potential confounders. A 1 standard deviation (SD) increase in plasma viscosity $(0.070 \mathrm{mPa} \cdot \mathrm{s})$ was associated with a $42 \%$ increase in the relative risk (RR 1.42 $95 \% \mathrm{CI}, 1.09-1.86$ ). Comparison of the RR for a CHD event in the top quintile to the risk in the bottom quintile yielded a more than 3-fold increased risk (RR 3.31, 95\% CI 1.19-9.25) [6].

There is a well-known north-south gradient in CHD incidence in Europe which cannot be explained on the basis of traditional risk factors. We therefore looked into the geographical variations of plasma viscosity in relation to coronary event rates in two regions with different absolute CHD risk, Glasgow in Scotland and Augsburg in Southern Germany. We analyzed plasma viscosity data from the S1 and compared them to values form Glasgow MONICA, collected in the same year. In multivariable adjusted analyses, we found a striking difference of a $1 \mathrm{SD}$ of the population mean $(0.066,95 \% \mathrm{CI}, 0.058-0.073)$ in men and a similar difference in women, with lower values in Augsburg compared to Glasgow. This large geographical difference may explain in part the differences in CHD event rates between these two populations [7].

In several publications using the data from S1, we reported positive associations between plasma viscosity and various lipoproteins [8], smoking [9], blood pressure [10], and a negative association with leisure-time physical activity [11]. Also, in postmenopausal women from the $\mathrm{S} 1$ we found decreased plasma viscosity values during hormonal replacement therapy [12].

In addition, we prospectively analyzed the association between plasma viscosity and total mortality in the same cohort and found a RR to die of 2.68 (95\% CI, 1.63-4.42) in subjects being in the top quintile of the plasma viscosity distribution compared to the bottom quintile [13].

In summary, plasma viscosity was strongly associated with CHD events and with total mortality in initially healthy middle-aged men from the general population.

\section{C-reactive protein (CRP)}

CRP, the classical acute phase protein, is a sensitive marker of inflammation, tissue damage and infection [14]. In contrast to virtually all other major acute phase reactants, its plasma half life $(\sim 19 \mathrm{~h})$ is rapid but is identical under all conditions, so that the synthesis rate of CRP is the sole determinant of its plasma concentration [15]. Excellent anti-CRP antibodies and a well estab- 
I6] are available so that precise, sensitive and robust clinical serum/ plasma assays can be readily undertaken $[17,18]$. The measurement of CRP thus has many advantages for detection and monitoring of the acute phase response in general and particularly in relation to atheroma and its complications. It should be mentioned that more than $95 \%$ of the general population show values below $10 \mathrm{mg} / \mathrm{L}$, about two thirds present with values below $3 \mathrm{mg} / \mathrm{L}$ and approximately one third of values are still below $1 \mathrm{mg} / \mathrm{L}$ [19]. Thus the majority of measurements, provided that other causes of elevated CRP are excluded, are well below the range previously thought to be of relevance in the clinical setting. In order to investigate the association between CRP levels and CHD risk in large, unselected population, we have measured serum CRP by a high-sensitivity (hs) immunoradiometric assay [20] in 936 initially healthy men aged 45-64 years, who took part in S1. Based on an 8-year follow-up, we found an almost threefold increase in risk of a first major coronary event in these men, if individuals in the top quintile of the CRP distribution were compared to the bottom quintile [21]. This study further showed that CRP, although an acute phase reactant with a relatively short half-life turned out to be a reliable long-term marker of risk.

In long-term observational epidemiologic studies, risk variables are usually measured once at "baseline" and then related to outcome. Most physiological variables however, are not stable over time, but rather show a more or less pronounced diurnal, seasonal, and long-term variability. The potential for long-term variability is of great importance since such variation may have considerable impact on the accuracy of risk prediction by particular analytes. Surprisingly little information is available about this aspect of even the conventional risk factors in adequately sized samples and over longer periods of time, and only few studies have investigated the hemostatic parameters commonly used in epidemiological studies. Since the acute phase response is nonspecific, highly sensitive, and is induced by a wide range of different processes, including most forms of tissue injury and infec- tion, long-term variability might be expected to be even more important for markers of inflammation than for other biovariables that are subject to such common and wide-ranging effects. In particular, for CRP, which is extremely sensitive and shows a dynamic range of up to 10,000 fold in response to a variety of stimuli, this information is needed to reliably assess the risk prediction associated with elevated values. We measured CRP by a hsassay in 936 men aged $45-64$ years in 1984/85 (S1), and re-measured it 3 years later in 696 men from the same cohort (response rate $74 \%$ ). All 936 men were subjected to an 8-year follow-up of their cardiovascular status. The analytical variation of the assay was small, with the analytical variance component (VC) at one percent of the within-subject VC, a repeatability coefficient of 25 percent, and a reliability coefficient of 1.00 , indicating extremely little analytical measurement error. In contrast, the withinsubject variability of CRP corresponded to a repeatability coefficient of 740 percent and a reliability coefficient of 0.54 , indicating considerable within-subject variation. Based on our estimates, three serial determinations of CRP should be done to achieve a reliability of 0.75 , the value we found for total cholesterol. Correcting the hazard rate ratios in our original analysis of the association of CHD and hs-CRP for the measurement error in CRP and covariables, leads to a considerably larger estimate. Our results suggest that the true association between CRP and cardiovascular risk is underestimated by a single CRP determination, and that several serial CRP measurements should be made [22].

An important issue in risk assessment relates to the potentially clinical relevant additional information conveyed by a new risk marker; in other words, does the addition of a new marker to the conventional risk profile enable improved risk prediction from a clinical standpoint? The Framingham Risk Sore (FRS) is recommended for global risk assessment in subjects prone to CHD, and we investigated the potential of CRP measurements to modify risk prediction based on the FRS in a large CHD-event free cohort of middle-aged white men of German nationality sampled from the general population (the population-based MONICA Augsburg studies (S1-S3), conducted between 1984/85 and

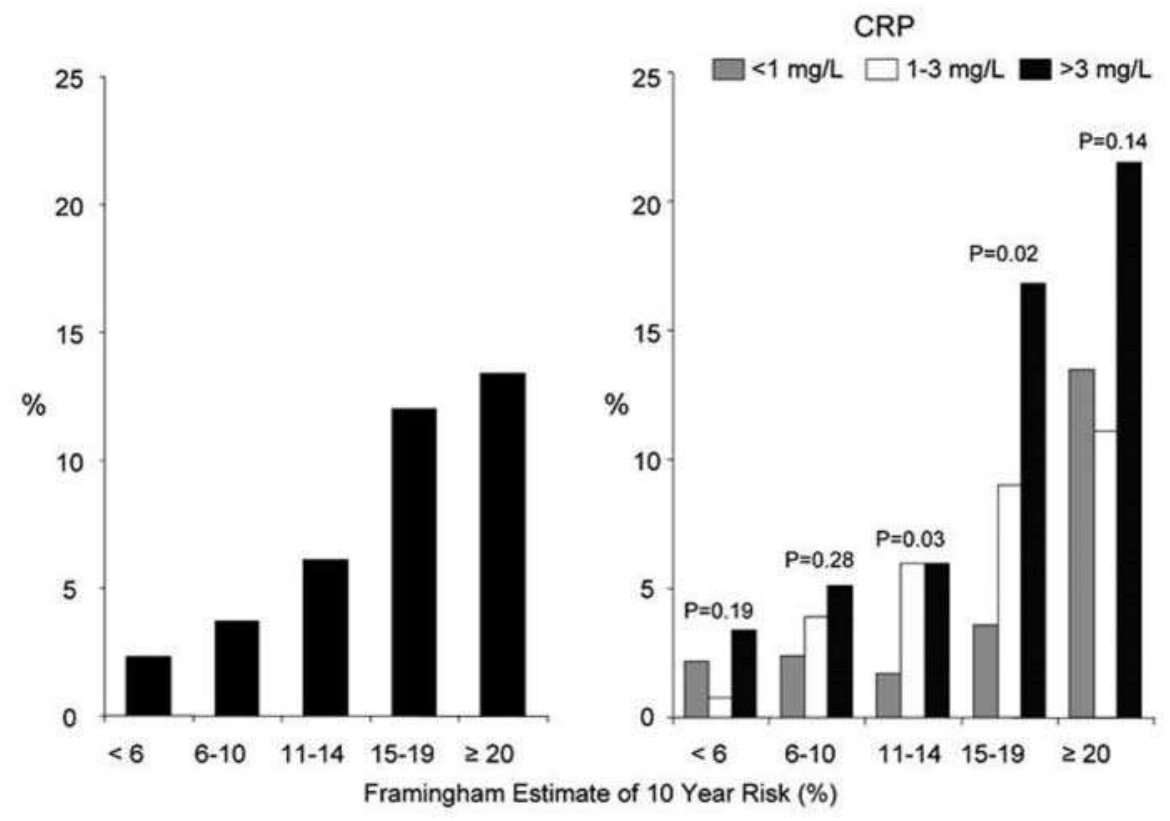

Koenig W et al. Systemic Low-Grade Inflammation ... Gesundheitswesen 2005; 67 Sonderheft 1: S62-S67
Fig. 1 Application of the Framingham Risk Score (FRS) alone and together with C-reactive protein (CRP) on the MONICA/KORA cohort data from 1984/85-1994/95 (S1-S3) including follow-up until 1998. Occurrence of a first coronary event within 10 years, estimated by Cox proportional hazards models in percentages. Left, Percentage estimated by a model with FRS (5 categories) adjusted for survey. Right, Percentage estimated for each of 5 FRS categories by a model with CRP (3 categories) adjusted for FRS (continuous) and survey. Probability values indicate significance status of CRP in the Cox model. 
1994/95 including morbidity and mortality follow-up in 1998 [23]). We compared the proportions of incident coronary events within 10 years estimated by the Cox model for the five categories of the FRS alone (Fig. 1, left panel) and for different CRP categories in each category of FRS, adjusted for survey and components of the FRS (Fig. 1, right panel). Probability values of the stratified analyses are given in Fig. 1 (right panel, above each FRS category). Cox regression revealed a considerable modification in coronary event incidence based on CRP concentrations and, more importantly, in categories of FRS associated with a $10 \%$ to $20 \%$ risk per 10 years, elevated concentrations of CRP were consistently and statistically significantly associated with a further increased risk $(P=0.03$ and $P=0.02)$. In contrast, in men with a risk $<6 \%$ and $6 \%$ to $10 \%$ per 10 years, CRP had no statistically significant additional effect on the prediction of a first coronary event. In ROC analyses, regarding the different areas under the curve (AUC), a remarkable increase was found for the intermediate FRS categories of $11 \%$ to $14 \%$ and $15 \%$ to $19 \%$ (increase in the AUC from 0.725 to 0.776 and from 0.695 to 0.751 ).

In this prospective population-based study, increased CRP concentrations and an elevated total cholesterol/HDL-cholesterol (TC/HDL-C) ratio were both independently related to incident coronary events. However, even if the strongest lipid/lipoprotein variable was chosen for risk assessment, these data clearly show that the measurement of CRP contributes significantly to the prediction of a first coronary event and adds clinically relevant information to the TC/HDL-C ratio. Finally, and most importantly, these prospective data from a large European cohort of middleaged men clearly suggest that CRP modulates the risk conveyed by the FRS as the hazard ratios (HRs) from the top to the bottom category decreased remarkably after inclusion of CRP in the various models. This was observed in particular in those with an FRS between $10 \%$ and $20 \%$ over a period of 10 years. These men may benefit from additional noninvasive tests such as determination of CRP by a hs assay.

Thus, our data suggest the inclusion of CRP as an additional variable to further improve risk prediction in asymptomatic subjects at intermediate risk of CHD. This would be in line with recent American Heart Association/Centers for Disease Control guidelines.

\section{Lipoprotein-associated phospholipase $A_{2}$ (Lp-PLA $)$}

Lipoprotein-associated phospholipase $\mathrm{A}_{2}\left(\mathrm{Lp}-\mathrm{PLA} \mathrm{A}_{2}\right)$ is an enzyme that may directly promote atherogenesis by generating potent pro-inflammatory and pro-atherogenic products, like lysophosphatidylcholine (lysoPC) and oxidized free fatty acids (oxFFA) from oxidation of LDL [24-26], an important step in atherogenesis. Lp-PLA 2 is produced mainly by the characteristic cells of the atherosclerotic plaque, namely monocytes/macrophages, T-lymphocytes, and mast cells $[27,28]$. Furthermore, Lp-PLA 2 has been detected in both human and rabbit atherosclerotic lesions [29]. Experimental studies in Watanabe heritable hyperlipidemic rabbits have demonstrated that inhibition of Lp-PLA 2 leads to the reduction of atherosclerotic lesion formation [30]. In the bloodstream, two-thirds of the Lp-PLA 2 plasma isoform circulates primarily bound to LDL, the other third is distributed between high-density lipoproteins (HDL) and very low-density lipoproteins (VLDL) [31]. On the other hand, this enzyme is also known as the platelet activating factor acetylhydrolase (PAF-AH) which may reflect its antiatherogenic activity: to catalyze the degradation of PAF and oxidized phospholipids; in HDL cholesterol in particular, Lp-PLA 2 has been suggested as a protective factor against the accumulation of oxidation products [32], thereby protecting LDL from further oxidation [33-35].

Indeed, data from three prospective epidemiologic studies assessing the association of Lp-PLA ${ }_{2}$ with cardiovascular endpoints yielded varying results [36-38]. We sought to investigate simultaneously the association between plasma concentrations of Lp$\mathrm{PLA}_{2}$, C-reactive protein (CRP), and long-term risk of CHD in initially healthy middle-aged men from the general population in Augsburg, Southern Germany.

Plasma concentrations of Lp-PLA 2 were determined by ELISA in 934 apparently healthy men aged 45-64 years sampled from S1 in 1984/85 and followed until 1998. During this period 97 men suffered from a coronary event diagnosed according to the MONICA protocol. Baseline levels of Lp-PLA 2 were higher in subjects who experienced an event compared to event-free subjects (295 \pm 113 vs. $263 \pm 79$ ng/mL, p < 0.01). Lp-PLA 2 was positively correlated with total cholesterol $(\mathrm{R}=0.30, \mathrm{p}<0.0001)$ and age $(\mathrm{R}=0.12, \mathrm{p}=0.001)$, and only slightly with HDL cholesterol $(R=0.09, p=0.005)$ and $C R P R=0.06, p=0.06)$, but not with body mass index and blood pressure. In a Cox model, a 1 SD increase in Lp-PLA 2 was associated with risk of future coronary events (hazard ratio, HR 1.37, 95\% confidence interval, CI 1.161.62). After controlling for potential confounders, the HR was attenuated, but still remained statistically significant (HR 1.23, $95 \% \mathrm{CI}, 1.02-1.47$ ). Further inclusion of C-reactive protein (CRP) in the model did not appreciably affect its predictive ability (HR $1.21 ; 95 \% \mathrm{CI}, 1.01-1.45)$. Elevated levels of Lp-PLA 2 appeared to be predictive of future coronary events in apparently healthy middle-aged men with moderately elevated total cholesterol, independent of CRP. This suggests that LP-PLA 2 and CRP may be additive in their ability to predict risk of coronary heart disease [39].

\section{Summary and outlook}

These data from the MONICA/KORA cohort studies, involving all three population-based surveys (S1-S3) between 1984/85 and $1994 / 95$ clearly show that various systemic markers of inflammation are able to predict future CHD events. For overview of published topics in the area of inflammation see Table 1 . Thus, the role of a low-grade systemic inflammatory response is strongly supported by these results. Large cohorts like MONICA/ KORA represent valuable databases for the evaluation of new risk markers that potentially will find their way into the clinical situation and contribute to an improved understanding of the pathophysiology of CHD and to improved risk prediction. As basic research progresses, new candidate markers in serum but also genetic markers related to the inflammatory response will be identified in the future and can be tested in these populations. 
Table 1 Systemic inflammation and risk of coronary heart disease: Overview of publications based on the MONICA/KORA studies

$\begin{array}{lll}\text { citation topic References } & \text { R }\end{array}$

\begin{tabular}{|c|c|c|c|}
\hline \multicolumn{4}{|l|}{ plasma viscosity } \\
\hline \multicolumn{4}{|c|}{ prospective studies } \\
\hline Koenig et al. & Arterioscler Thromb Vasc Biol 1998; 18: 768-772 & Plasma viscosity and the risk of CHD & 6 \\
\hline Koenig et al. & $\mathrm{Br}$ J Haematol 2000; 109: 453-458 & Plasma viscosity and all-cause mortality & 13 \\
\hline \multicolumn{4}{|c|}{ cross-sectional studies } \\
\hline Ernst et al. & Arteriosclerosis 1988; 8: $385-388$ & Plasma viscosity in healthy cigarette smokers & 9 \\
\hline Koenig et al. & Am J Hypertens 1991; 4: 529-536 & Plasma viscosity and blood pressure & 10 \\
\hline Koenig et al. & Circulation 1992; 85: $2197-2204$ & Plasma viscosity and lipoproteins & 8 \\
\hline Koenig et al. & Lancet 1994; 344: 711-714 & Geographical variations in plasma viscosity & 7 \\
\hline Koenig et al. & Circulation 1997; 95: $335-341$ & Plasma viscosity and leisure-time physical activity & 11 \\
\hline Peters et al. & Lancet 1997; 349: $1582-1587$ & Plasma viscosity during an air pollution episode & - \\
\hline Fröhlich et al. & Br J Haematol 1998; 100: $577-581$ & HRT and plasma viscosity in postmenopausal women. & 12 \\
\hline \multicolumn{4}{|l|}{ C-reactive protein } \\
\hline \multicolumn{4}{|c|}{ prospective studies } \\
\hline Koenig et al. & Circulation 1999; 99: 237-242 & CRP and future risk of coronary heart disease & 21 \\
\hline Koenig et al. & Am J Epidemiol 2003; 158: 357-364 & CRP within-subject variation and risk of CHD & 22 \\
\hline Thorand et al. & Arch Intern Med 2003; 163: 93-99 & CRP and incident diabetes mellitus & - \\
\hline Ladwig et al. & Brain Behav Immun 2003; 17: 268-275 & CRP, obesity and depressive mood & - \\
\hline Koenig et al. & Circulation 2004; 109: 1349-1353 & CRP adds to the Framingham score & 23 \\
\hline \multicolumn{4}{|c|}{ cross-sectional studies } \\
\hline Fröhlich et al. & Fibrinolysis and Proteolysis 1999; 13: 239-244 & CRP and oral contraceptive use & - \\
\hline Hutchinson et al. & Clin Chem 2000; 46: 934-348 & Immunoradiometric assay of circulating CRP & 20 \\
\hline Peters et al. & Eur Heart J 2001; 22: 1198-1204 & CRP and particulate air pollution & - \\
\hline Fröhlich et al. & Clin Chem 2002; 48: 575-577 & Seasonal variation in CRP & - \\
\hline Fröhlich et al. & Eur Heart J 2003; 24: 1365 - 1372 & Various smoking characteristics and CRP & - \\
\hline Fröhlich et al. & Ann Med 2003; 35: 353-361 & CRP in women on different HRT & - \\
\hline Imhof et al. & Clin Chem 2003; 49: 669-672 & CRP distribution in various MONICA populations & 19 \\
\hline Döring et al. & Atherosclerosis 2004; 172: $281-286$ & Third generation oral contraceptive and CRP & - \\
\hline Imhof et al. & Eur Heart J 2004; 25: $2092-2100$ & Overall alcohol intake, beer, wine, and CRP & - \\
\hline \multicolumn{4}{|c|}{$\begin{array}{l}\text { lipoprotein-associated phospholipase } A_{2} \\
\text { prospective studies }\end{array}$} \\
\hline Koenig et al. & Circulation 2004; 110: $1903-1908$ & Lp-PLA ${ }_{2}, C R P$ and incident coronary events & 39 \\
\hline \multicolumn{4}{|l|}{ oxidized LDL } \\
\hline \multicolumn{4}{|c|}{ prospective studies } \\
\hline Meisinger et al. & Circulation 2004; 10 (suppl III), III-808. Abstract no. 3734 & Oxidized LDL and CHD events & - \\
\hline
\end{tabular}

$C H D=$ coronary heart disease; $C R P=C$-reactive protein; $H R T=$ hormone replacement therapy; $L p-P L A_{2}=$ lipoprotein-associated phospholipase $A_{2} ; L D L=$ low density lipoprotein

\section{Acknowledgement}

These investigations have been supported by GSF and grants from BMBF - Bundesministerium für Bildung und Forschung (01GS0423 and NGFN), DFG-Forschungsgemeinschaft (TH784/ 2-1).

\section{References}

${ }^{1}$ Ross R. Atherosclerosis - An inflammatory disease. N Engl J Med 1999; 340: $115-126$

2 van der Wal AC, Becker AE, van der Loos CM et al. Site of intimal rupture or erosion of thrombosed coronary atherosclerotic plaques is characterized by an inflammatory process irrespective of the dominant plaque morphology. Circulation 1994; 89: 36- 44

3 Torzewski J, Torzewski M, Bowyer DE et al. C-reactive protein frequently colocalizes with the terminal complement complex in the intima of early atherosclerotic lesions of human coronary arteries. Arterioscler Thromb Vasc Biol 1998; 18: 1386-1392
${ }^{4}$ Libby P. Molecular bases of acute coronary syndromes. Circulation 1995; 91: $2844-2850$

${ }^{5}$ Ridker PM, Glynn RJ, Hennekens $\mathrm{CH}$. C-reactive protein adds to the predictive value of total and HDL cholesterol in determining risk of first myocardial infarction. Circulation 1998; 97: 2007-2011

${ }^{6}$ Koenig W, Sund M, Filipiak B et al. Plasma viscosity and the risk of coronary heart disease: results from the MONICA-Augsburg Cohort Study, 1984 to 1992. Arterioscler Thromb Vasc Biol 1998; 18: 768 - 772

${ }^{7}$ Koenig W, Sund M, Lowe GD et al. Geographical variations in plasma viscosity and relation to coronary event rates. Lancet 1994; 344 : 711 714

${ }^{8}$ Koenig W, Sund M, Ernst E et al. Association between rheology and components of lipoproteins in human blood. Results from the MONICA project. Circulation 1992; 85: 2197 -2204

${ }^{9}$ Ernst E, Koenig W, Matrai A et al. Blood rheology in healthy cigarette smokers. Results from the MONICA project, Augsburg. Arteriosclerosis 1988; 8: 385-388

${ }^{10}$ Koenig W, Sund M, Ernst E et al. Association between plasma viscosity and blood pressure. Results from the MONICA-project Augsburg. Am J Hypertens 1991; 4: 529-536 
${ }^{11}$ Koenig W, Sund M, Doring A et al. Leisure-time physical activity but not work-related physical activity is associated with decreased plasma viscosity. Results from a large population sample. Circulation 1997; 95: 335-341

${ }^{12}$ Frohlich M, Schunkert H, Hense HW et al. Effects of hormone replacement therapies on fibrinogen and plasma viscosity in postmenopausal women. Br J Haematol 1998; 100: 577-581

${ }^{13}$ Koenig W, Sund M, Lowel H et al. Association between plasma viscosity and all-cause mortality: results from the MONICA-Augsburg Cohort Study 1984-92. Br J Haematol 2000; 109: 453-458

${ }^{14}$ Pepys MB. The acute phase response and C-reactive protein. In: Weatherall DJ, Ledingham JGG, Warrell DA (ed). Oxford Textbook of Medicine. Oxford, UK: Oxford University Press, 1995: 1527-1533

15 Vigushin DM, Pepys MB, Hawkins PN. Metabolic and scintigraphic studies of radioiodinated human C-reactive protein in health and disease. J Clin Invest 1993; 91: 1351 - 1357

${ }^{16}$ WHO Expert Committee on Biological Standardization. WHO Technical Report Series 760. Geneva, Switzerland, 1987

${ }^{17}$ Macy EM, Hayes TE, Tracy RP. Variability in the measurement of C-reactive protein in healthy subjects: implications for reference intervals and epidemiological applications. Clin Chem 1997; 43: 52 - 58

${ }^{18}$ Wilkins J, Gallimore JR, Moore E et al. Rapid automated high sensitivity enzyme immunoassay of C-reactive protein. Clin Chem 1998; 44: $1358-1361$

${ }^{19}$ Imhof A, Frohlich M, Loewel H et al. Distributions of C-reactive protein measured by high-sensitivity assays in apparently healthy men and women from different populations in Europe. Clin Chem 2003; 49: $669-672$

${ }^{20}$ Hutchinson WL, Koenig W, Frohlich M et al. Immunoradiometric assay of circulating C-reactive protein: age-related values in the adult general population. Clin Chem 2000; 46: 934-938

${ }^{21}$ Koenig W, Sund M, Frohlich M et al. C-reactive protein, a sensitive marker of inflammation, predicts future risk of coronary heart disease in initially healthy middle-aged men: results from the MONICA (Monitoring Trends and Determinants in Cardiovascular Disease) Augsburg Cohort Study, 1984 to 1992. Circulation 1999; 99: 237-242

${ }^{22}$ Koenig W, Sund M, Frohlich M et al. Refinement of the association of serum C-reactive protein concentration and coronary heart disease risk by correction for within-subject variation over time: the MONICA Augsburg studies, 1984 and 1987. Am J Epidemiol 2003; 158: $357-$ 364

${ }^{23}$ Koenig W, Lowel H, Baumert J et al. C-reactive protein modulates risk prediction based on the Framingham Score: implications for future risk assessment: results from a large cohort study in southern Germany. Circulation 2004; 109: 1349-1353

${ }^{24}$ Caslake MJ, Packard CJ. Lipoprotein-associated phospholipase A2 (platelet-activating factor acetylhydrolase) and cardiovascular disease. Curr Opin Lipidol 2003; 14: 347-352

25 Tselepis AD, Chapman JM. Inflammation, bioactive lipids and atherosclerosis: potential roles of a lipoprotein-associated phospholipase A2, platelet activating factor-acetylhydrolase. Atherosclerosis 2002; Suppl 3: $57-58$ 